\title{
ANALYSIS OF 6-MERCAPTOPURINE AND 6-METHYLMERCAPTOPURINE IN DRIED BLOOD SPOTS USING LIQUID CHROMATOGRAPHY-TANDEM MASS SPECTROMETRY AND ITS APPLICATION IN CHILDHOOD ACUTE LYMPHOBLASTIC LEUKEMIA PATIENTS
}

\author{
SUPANDI SUPANDI ${ }^{1,2 *}$, YAHDIANA HARAHAP ${ }^{1}$, HARMITA HARMITA ${ }^{1}$, RIZKA ANDALUSIA ${ }^{3}$, MARLINA IKA ${ }^{1}$ \\ ${ }^{1}$ Department of Pharmacy, Faculty of Pharmacy, Universitas Indonesia, Depok Campus 16424, Indonesia. ${ }^{2}$ Department of Pharmacy, \\ Faculty of Pharmacy and Science, UHAMKA, Jakarta, Indonesia. ${ }^{3}$ Department of Research and Development, Dharmais Cancer Hospital, \\ Jakarta 11420, Indonesia. Email: supandiuhamka@gmail.com
}

Received: 09 May 2017, Revised and Accepted: 22 May 2017

ABSTRACT

Objective: To analyze and validate 6-mercaptopurine (6-MP) and 6-methylmercaptopurine (6-MMP) in dried blood spots (DBS) using liquid chromatography-tandem mass spectrometry (LC/MS-MS).

Methods: Bio-sampling dried blood spot with DBS-CAMAG ${ }^{\circledR}$ paper diameter of $8 \mathrm{~mm}$ and extracted with acetonitrile-methanol (1:3) containing internal standard 5-fluorouracil (5-FU). Separation was performed with $\mathrm{C}_{18}$ column Acquity ${ }^{\circledR} 1.7 \mu \mathrm{m}(2.1 \mathrm{~mm} \times 100 \mathrm{~mm})$, with a mobile phase mixture of $0.1 \%$ formic acid in water $0.1 \%$ formic acid in acetonitrile with gradient elution and flow rate $0.2 \mathrm{ml} / \mathrm{min}$. Mass detection was Waters Xevo TQD with positive electrospray ionization (ESI) for 6-MP, 6-MMP and negative ESI for 5-FU in multiple reaction monitoring modes. The ions of 6-MP was detected at $\mathrm{m} / \mathrm{z}$ 153.09->119.09, 6-MMP at m/z 167.17->126.03, and 5-FU at m/z 129.15->42.05.

Results: This method fulfill the requirements of selectivity, linearity, lower limit of quantification, accuracy, precision, carry-over, matrix effects, and stability which refers to the european medicines agency (EMEA) guidelines. The linearity of 0.99 was $26-1000 \mathrm{ng} / \mathrm{mL}$ for 6-MP and 6-MMP, respectively. The validated method was applied to two childhood ALL maintenance phase. Retrieved 6-MP levels of $10.37 \mathrm{pmol} / 8 \times 10^{8}$ erythrocytes, respectively. The levels of 6-MMP gained 16.59 pmol/ $8 \times 10^{8}$ erythrocytes, respectively.

Conclusion: The developed LC/MS-MS method is valid to analysis 6-MP and 6-MMP in DBS simultaneous in vitro according to EMEA guidelines. The method was successfully applied to authentic capillary blood samples from two childhood patients with ALL in the maintenance phase.

Keywords: 6-mercaptopurine, 6-methylmercaptopurine, Dried blood spots, Acute lymphoblastic leukemia.

(c) 2017 The Authors. Published by Innovare Academic Sciences Pvt Ltd. This is an open access article under the CC BY license (http://creativecommons. org/licenses/by/4. 0/) DOI: http://dx.doi.org/10.22159/ajpcr.2017.v10i9.19790

\section{INTRODUCTION}

6-mercaptopurine (6-MP) is an antineoplastic drug which belongs to antimetabolites drug and widely used in childhood acute lymphoblastic leukemia (ALL) medication in single or combination dose [1]. It is a prodrug with individual dose based on patient's body surface are because of the reason, the administration of the drug should be monitored. The usual bio-sampling method for therapeutic drug monitoring is performed through a vein (venipuncture) [2]. This method has many disadvantages such as requires a large volume, inefficient in storage and distribution, need experts to obtain the blood, and painful to the patients $[3,4]$. Dried blood spot (DBS) sampling has many potential advantages such as minimum invasive because using a sterile lancet needle in the fingers, toes or heel, small sample volumes ranging from 10 to $80 \mu \mathrm{l}$, efficient storage and distribution, prolonged sample stability, lower risk of infections, and comfortable for the subject $[5,6]$. Because the sample is taken from a peripheral vein in small volume, causing the analyte and the hematocrit interfering with the quantitative analysis of the drug molecule. Therefore, it needs rapid, sensitive, and selective method for quantification with liquid chromatography-tandem mass spectrometry (LC-MS/MS) [7-9].

Analysis of 6-MP and its metabolites in erythrocytes and plasma using high performance liquid chromatography (HPLC) and LC-MS/MS has been developed $[1,10]$. There is no report described the development of an analytical method to determine 6-MP in DBS. The novelty of the research is describes a simple, rapid, sensitive, and selective LC-MS/MS method for determining 6-MP and 6-methylmercaptopurine (6-MMP) in DBS and its application of this method in childhood ALL patients. This study performed assay validations, according to the european medicines agency (EMEA) guidelines [11].

\section{METHODS}

Chemicals and materials

6-MP $\left(\mathrm{C}_{5} \mathrm{H}_{4} \mathrm{~N}_{4} \mathrm{~S}\right)$, 6-MMP $\left(\mathrm{C}_{6} \mathrm{H}_{6} \mathrm{~N}_{4} \mathrm{~S}\right)$, and 5-fluorouracil (5-FU) $\left(\mathrm{C}_{4} \mathrm{H}_{3} \mathrm{~N}_{2} \mathrm{O}_{2} \mathrm{~F}\right)$ were purchased from Sigma-Aldrich (St. Louis, MO, USA), acetonitrile and methanol of HPLC grade were purchased from Merck (USA), purified water was prepared by a Millipore Direct-QTM 5 water system (Millipore, Watford, UK), sampling paper DBS w

as purchased from CAMAG, and whole blood from a blood bank (Indonesian Red Cross, Indonesia).

\section{Instrument and chromatographic condition}

The chromatography was performed on Waters Acquity ${ }^{\circledR}$ UPLC bridged ethylene hybrid $\mathrm{C}_{18}$ column $1.7 \mu \mathrm{m}(2.1 \mathrm{~mm} \times 100 \mathrm{~mm})$. The flow rate was $0.2 \mathrm{ml} / \mathrm{min}$ using a gradient elution starting with $95 \%$ water with $0.1 \%$ formic acid and $5 \%$ acetonitrile with $0.1 \%$ formic acid. The mass selective detector operated in electrospray ionization positive mode for 6-MP and 6-MMP, a negative mode for internal standard (IS) 5-FU as internal standard (IS). Mass spectrometric detection was performed on Waters Xevo TQD Triple Quadrupole (Waters, Milford, USA); multiple reaction monitoring was employed with mass resolutions of wide for MS1 and widest for MS2. High purity nitrogen was used as source and collision gas. For data analysis, Waters Masslynx 
software was used.

\section{Standard solutions}

All stock solutions were prepared using ammonium hydroxide at a concentration of $1.0 \mathrm{mg} / \mathrm{ml}$ and stored at $-20^{\circ} \mathrm{C}$, for calibration curve standard the stock solutions were diluted to yield 6-MP concentrations of $26-1000 \mathrm{ng} / \mathrm{ml}$ and 6-MMP concentrations of $13-500 \mathrm{ng} / \mathrm{ml}$.

\section{DBS sample preparation and extraction}

An aliquot of $40 \mu$ l spiked blood was spotted on the sampling paper with a graded capillary tube and dried for a minimum of $3 \mathrm{~h}$. Cut the spot with $8 \mathrm{~mm}$ diameter. After that transferred it into a $5 \mathrm{ml}$ polypropylene tube, add $100 \mu \mathrm{l}$ IS, then extract it with $3 \mathrm{ml}$ methanol and $1 \mathrm{ml}$ acetonitrile, vortex for about $30 \mathrm{~s}$ and sonicated for $25 \mathrm{~min}$ at $60^{\circ} \mathrm{C}$ temperature, then centrifuged (room temperature, $3100 \times g, 15 \mathrm{~min}$ ). Supernatant transferred in the sample tube and evaporated under a gentle stream of nitrogen at $40^{\circ} \mathrm{C}$ temperature. After reconstituting the extract with $100 \mu \mathrm{l}$ mobile phase, vortex for about $30 \mathrm{~s}$ and centrifuge (room temperature, $3100 \times g, 5 \mathrm{~min}$ ), $10 \mu \mathrm{l}$ of each sample was analyzed by LC-MS/MS.

\section{Method validation}

Assay validation was performed according to the EMEA guidelines for validation of bioanalytical assays [11]. In addition, experiments were conducted to determine the effects of volume of blood used to prepare the DBS, the effects of different hematocrit values, and the effects of DBS on the selectivity, carry-over, lower limit of quantitation, calibration curve, accuracy, precision, dilution integrity, matrix effect, and stability of the method.

\section{Application of the method to authentic samples}

Capillary blood from two patients spotted on a sampling paper and dried for at least $3 \mathrm{~h}$. After drying, then the spots were packed in a sealed plastic bag with desiccant and stored at room temperature until analysis as described above.

The study protocol was approved by the Committee of the Medical Research Ethics of the "Dharmais" Cancer Hospital, with a KEPK/019/ IV/2016 reference number for notice of approval.

\section{RESULTS}

Blood sampling procedure

For a sampling of an actual blood volume, we screened from several volumes; then, the spiked blood was spotted on papers DBS is $20 \mu \mathrm{l}$, $40 \mu \mathrm{l}$, and $80 \mu \mathrm{l}$. Accurate blood volume spotted on DBS card $40 \mu \mathrm{l}$.

\section{Optimizing sample preparation}

Extraction process from DBS sample is optimized by following parameters composition and volume of extraction, solution temperature and time of sonication. The preparation method was chosen based on area IS an analyte. The first experiment was performed with acetonitrile $1 \mathrm{ml}, 1.5 \mathrm{ml}$, methanol $1 \mathrm{ml}, 1.5 \mathrm{ml}$ of methanol and a mixture of both as much as $1 \mathrm{ml}$. The recovery obtained from all the method above was unqualified. Therefore, for further optimization, we add variation in composition and volume of extraction solution, and the best recovery obtained in the mix methanol-acetonitrile (3:1) in increments of $4 \mathrm{ml}$ (Fig. 1).

The recovery of 6-MP and 6-MMP was low on the organic solvent, due to different polarity between analyte and solvent. To overcome the shortcomings regarding solubility, we optimized the sonication temperature. Increasing the temperature of sonication is expected to increase the solubility of analyte in methanol and acetonitrile. Temperatures then optimized by $50^{\circ} \mathrm{C}, 60^{\circ} \mathrm{C}$, and $65^{\circ} \mathrm{C}$, respectively, for $30 \mathrm{~min}$. The optimum temperature is $60^{\circ} \mathrm{C}$ (Table 1), increasing the temperature of sonication resulting a significant increase in area. It is believed that temperature is increasing the solubility of the analyte, so the amount that also extracted increases. After the temperature is optimized, we optimized the time of sonication in 15,25 , and $30 \mathrm{~min}$, the optimum is $25 \mathrm{~min}$. The increased time of sonication will lower 6-MP area, but increasing 6-MMP area.

\section{Validation assay}

\section{Selectivity and hematocrit}

The selectivity of the method was determined with blank blood spots and spiked blood spots for lower limit of quantification (LLOQ) concentration from six different blood lots. The proportion of cells in a blood sample is termed hematocrit; there are no definitive levels for normal human hematocrit value, as the levels change with age, sex, and general health. The optimized methods were selective for 6-MP and 6-MMP in different hematocrit value $(25 \%, 35 \%, 40 \%, 45 \%$, and $50 \%$ ); no interfering signals were observed (Figs. 2 and 3). Selectivity was $9.93 \%$ coefficient of variation (CV) and $-16.6-11.28 \%$ diff for 6-MP, $12.85 \% \mathrm{CV}$ and $-17.71-15.37 \%$ diff for 6-MMP.

\section{Carry-over}

Carry-over should be assessed by injecting blank samples after a high concentration sample or calibration standard at the upper limit of quantification. Spiked quality control samples containing the analytes in concentrations representing the top range of the calibration standard were extracted and analyzed $(n=5)$. Immediately after injection of the high concentration quality control sample, a blank matrix sample was injected. The analyte measured in the blank matrix samples was required to be $\leq 20 \%$ of the LLOQ for the IS $\leq 5 \%$. No carry-over was observed for any of the analytes including the IS (Table 2).

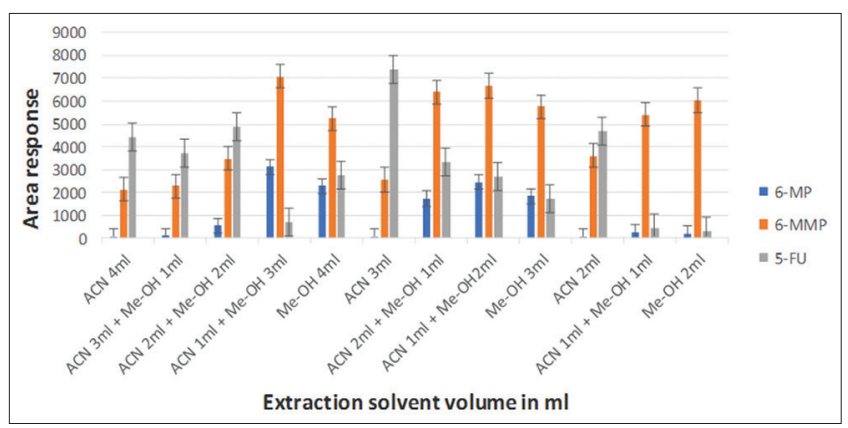

Fig. 1: Influence of the extraction acetonitrile (ACN) and methanol (Me-oh) on the analyte response peaks

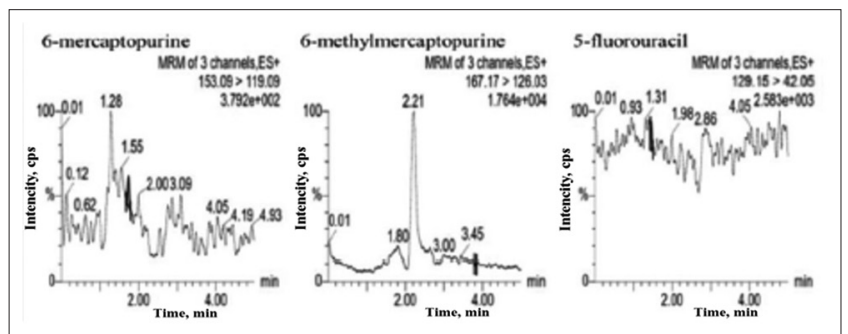

Fig. 2: Chromatograms showing the result of the extraction of blank

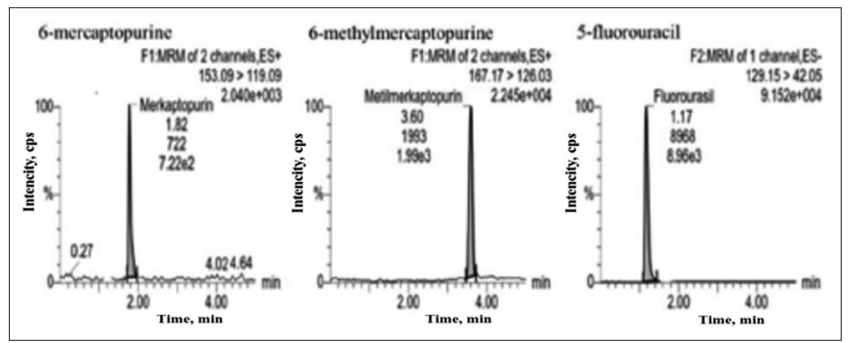

Fig. 3: Chromatograms showing the result of the extraction of lower limit of quantification 
Table 1: Optimized temperature of sonication

\begin{tabular}{|c|c|c|c|c|c|c|}
\hline \multirow[t]{2}{*}{ Sonication temperature } & \multicolumn{3}{|l|}{ Area } & \multicolumn{3}{|c|}{ Time retention (min) } \\
\hline & 6-MP & 6-MMP & 5-FU & 6-MP & 6-MMP & 5-FU \\
\hline $50^{\circ} \mathrm{C}$ & $27,984 \pm 75.78$ & $59,098 \pm 85.15$ & $10,670 \pm 46.07$ & $1.76 \pm 0.12$ & $3.78 \pm 1.01$ & $1.57 \pm 1.21$ \\
\hline $65^{\circ} \mathrm{C}$ & $20,873 \pm 59.10$ & $79,578 \pm 98.99$ & $4853 \pm 47.78$ & $1.73 \pm 1.11$ & $3.76 \pm 1.21$ & $1.57 \pm 1.11$ \\
\hline
\end{tabular}

Each value in the table was represented as mean \pm SD $(n=3)$. SD: Standard deviation, 6-MP: 6-mercaptopurine, 6-MMP: 6-methylmercaptopurine, 5-FU: 5-fluorouracil

Table 2: Parameters of carry-over

\begin{tabular}{llll}
\hline Parameters & $\begin{array}{l}\text { Mean } \\
\text { measured } \\
\text { blank area }\end{array}$ & $\begin{array}{l}\text { Mean } \\
\text { measured } \\
\text { LLOQ area }\end{array}$ & $\begin{array}{l}\text { Mean } \\
\text { measured } \\
\text { carry-over (\%) }\end{array}$ \\
\hline 6-MP & $100.80 \pm 50.61$ & $713.51 \pm 46.74$ & $14.05 \pm 6.69$ \\
6-MMP & $70.20 \pm 27.44$ & $1973.92 \pm 120.32$ & $3.57 \pm 1.43$ \\
5-FU & $78.8 \pm 68.01$ & $7236.88 \pm 182.46$ & $1.08 \pm 0.94$ \\
\hline
\end{tabular}

Each value in the table was represented as mean \pm SD $(n=5)$. SD: Standard

deviation, 6-MP: 6-mercaptopurine, 6-MMP: 6-methylmercaptopurine,

5-FU: 5-fluorouracil, LLOQ: Lower limit of quantification

\section{Calibration curve, linearity, and LLOQ}

A calibration curve was prepared for 5 consecutive days. The relationship between the quotient peak area of the analyte/peak area of the IS and the concentration was linear for 6-MP, and 6-MMP within the range of the calibration curve. Linearity was evaluated by comparing the slopes of the calibration curves. The coefficients of correlation (6-MP $\geq 0.99$ for $26-1000 \mathrm{ng} / \mathrm{ml}, 6-\mathrm{MMP} \geq 0.99$ for $13-500 \mathrm{ng} / \mathrm{ml}$ ) were determined. For determination of the LLOQ quality control samples with low concentrations were analyzed $(n=5)$. The LLOQ, defined as the lowest concentrations that could be determined with a precision displaying a \% CV and \% diff of $\leq 20 \%$. The LLOQ is $26 \mathrm{ng} / \mathrm{ml}$ for 6 -MP and $13 \mathrm{ng} / \mathrm{ml}$ for 6-MMP. The purpose of the development of this method is the monitoring of drug therapy, where the levels of drug $\mathrm{C}_{\text {max }}$ was taken at the time so that the LLOQ on this dry blood sample can be used for monitoring therapeutic drug 6MP for achievements LLOQ meet in the range of $\mathrm{C}_{\text {max }}$

\section{Accuracy and precision}

Within-run and between-run precision and accuracy were calculated from data obtained during a $3 \mathrm{~d}$ validation period. Each the $3 \mathrm{~d}$ sample spiked with the chosen concentrations (each concentration $n=5$ ) were analyzed. Four selected concentrations covered a high, medium and low range and the lower limit of quantification of the calibration curve. Accuracy was evaluated by calculating the difference between measured values and nominal values (\% diff); precision was calculated based on the \% CV. Within-run accuracy and precision, respectively, were $-12.76-11.90 \%$ diff and $3.79-6.95 \%$ CV for 6-MP. For 6-MMP $-19.92-9.41 \%$ diff and $13.15-6.13 \%$ CV. The between-run accuracy and precision ranged between $-15.40-17.96 \%$ diff and $3.09-9.22 \% \mathrm{CV}$ for 6-MP, $-15.52-19.62 \%$ diff and $0.91-4.28 \%$ CV for 6-MMP. Therefore, all analytes were detected with sufficient accuracy and precision $( \pm 20 \%$ for LLOQ, $\pm 15 \%$ for quality control low concentration [QCL], quality control medium concentration, and quality control high concentration [QCH]) (accuracy and precision data in Tables 3 and 4).

\section{Matrix effects}

Matrix effects were investigated for 6-MP and 6-MMP using 6 lots of individual human blood. The matrix factors (MF) were calculated for 6-MP and 6-MMP to obtain the IS normalized MF (MEIS). The response of post-spiked samples with known concentrations (QCL, and QCH) was compared with the response of non extracted solutions of the analyte at corresponding concentrations. The IS normalized MFs (MEIS) were found to be $8.40-10.06 \% \mathrm{CV}$ for $6-\mathrm{MP}$ and $7.66-8.07 \% \mathrm{CV}$ for 6-MMP, and therefore the variability was within acceptable limits (Table 5).

\section{Dilution integration}

This parameter aims to see that the dilution of samples in the analysis affect the accuracy and precision or not. Integrity dilution demonstrated by spiking the matrix with the analyte concentration above upper limit of quantification (ULOQ) and diluting this mixture with blank matrix (at least five determinations per dilution factor). Dilution integrity at half ULOQ was $11.37 \%$ CV and $-6.68-13.55 \%$ diff for 6-MP, $6.58 \% \mathrm{CV}$ and $-13.36-4.30 \%$ diff for 6-MMP. At a concentration quarter, ULOQ was $3.14 \% \mathrm{CV}$ and $5.73-13.88 \%$ diff for 6-MP, 9.49\% CV and $-10.14-4.30 \%$ diff for 6-MMP. Therefore, all analytes were detected with sufficient accuracy $( \pm 15 \%$ relative error of the nominal value) and precision (within $15 \%$ relative standard deviation).

\section{Stability}

The stock solution stability was determined for one concentrations $(1 \mathrm{mg} / \mathrm{ml}$; each concentration $\mathrm{n}=5)$ under different conditions. Store the solution in room temperature for $24 \mathrm{~h}$ and at $-20^{\circ} \mathrm{C}$ for $16 \mathrm{~d}$. All solutions were stable under these conditions. The accuracy and precision was $0.21-0.60 \% \mathrm{CV}$ and $-0.34-0.43 \%$ diff for 6-MP, $0.04-$ $0.93 \%$ CV and $-0.03-0.66 \%$ diff for 6-MMP, $0.09-2.54 \%$ CV and $-0.06-$ $1.80 \%$ diff for 5 -FU (Table 6 ).

To the determine the short-term stability, store the DBS in sealed plastic bags containing silica gel desiccants for $24 \mathrm{~h}$, then determined by analyzing blood spots containing the analytes at two concentrations (QCL and QCH; each concentration $\mathrm{n}=3$ ). The calculated concentrations, accuracy, and precision between samples immediately after drying for $3 \mathrm{hrs}$ and the different time were determined and compared. The accuracy and precision was $2.64-8.20 \% \mathrm{CV}$ and $-8.61-12.24 \%$ diff for 6-MP, 4.25-6.42\% CV and -14.11-13.72\% diff for 6-MMP (Table 7).

The stability of the extracted samples in the autosampler for $24 \mathrm{~h}$ was determined by analyzing blood spots containing the analytes at two concentrations (QCL and QCH; each concentration $\mathrm{n}=3$ ). The calculated concentrations, accuracy, and precision between samples measure immediately after extraction and samples remaining in the autosampler for $24 \mathrm{~h}$ until measurement were calculated and compared. The accuracy and precision was $2.79-5.47 \% \mathrm{CV}$ and $-5.33-13.23 \%$ diff for 6-MP, $1.60-4.90 \% \mathrm{CV}$, and $-14.59-13.79 \%$ diff for 6-MMP. The result indicates that the compounds in the DBS and extracted samples were stable under the tested conditions (Table 8).

\section{Analysis of authentic capillary blood samples from DBS}

Subjects, were included, in this study are patients with ALL in children who are undergoing treatment in the maintenance phase. Retrieved two patients indicated its willingness to be a subject. Samples then carried out to the preparation and analyzed with methods that have been validated. The concentration of 6-MP found in erythrocytes were 6.69 and $10.37 \mathrm{pmol} / 8 \times 10^{8}$ erythrocytes, for 6-MMP were 6.02 and $16.59 \mathrm{pmol} / 8 \times 10^{8}$ erythrocytes (with $3.91 \times 10^{8}$ and $4.33 \times 10^{8}$ erythrocytes per $100 \mu \mathrm{l}$ of packed erythrocytes in patient 1 and 2).

\section{DISCUSSION}

Accurate blood volume spotted on DBS cards $40 \mu \mathrm{l}$ and it is spread evenly and absorbed rapidly. As for extraction method, we choose protein precipitation using methanol-acetonitrile (3:1) good recovery the analytes (Fig. 1). As shown in Table 1, its indicated sonication and evaporation step following the precipitation were added to concentrate its analyte they increase the response of analyte. Recovery of 6-MP and 6-MMP more than 90\%, it concludes that the extraction method was successful producing high extraction yield. Validation assay was 
Table 3: Accuracy and precision of 6-MP

\begin{tabular}{|c|c|c|c|c|}
\hline Analyte & Actual concentration ( $\mathrm{ng} / \mathrm{ml})$ & $\begin{array}{l}\text { Mean measured } \\
\text { concentration }(\mathrm{ng} / \mathrm{ml}) \pm S D(n=5)\end{array}$ & Precision (\% CV) & Bias (\% difference) \\
\hline \multirow[t]{4}{*}{ Within-run } & LLOQ (26) & $25.56 \pm 1.74$ & 6.82 & $(-10.17-8.36)$ \\
\hline & QCL (104) & $103.59 \pm 3.82$ & 3.69 & $(-4.36-4.28)$ \\
\hline & QCM (520) & $539.73 \pm 21.07$ & 3.90 & $(-0.11-8.99)$ \\
\hline & QCH (820) & $877.70 \pm 44.07$ & 5.03 & $(-0.67-14.07)$ \\
\hline \multirow[t]{3}{*}{ Between-run } & LLOQ (26) & $25.36 \pm 2.86$ & 11.29 & $(-14.04-17.06)$ \\
\hline & QCL (104) & $98.26 \pm 3.72$ & 3.78 & $(-12.08-3.21)$ \\
\hline & QCH (820) & $806.81 \pm 57.56$ & 7.13 & $(-13.59-13.34)$ \\
\hline
\end{tabular}

LLOQ: Lower limit of quantification, QCL: Quality control low concentration, QCM: Quality control medium concentration, QCH: Quality control high concentration, 6-MP: 6-mercaptopurine, SD: Standard deviation, CV: Coefficient of variation

Table 4: Accuracy and precision of 6-MMP

\begin{tabular}{|c|c|c|c|c|}
\hline Analyte & Actual concentration ( $\mathrm{ng} / \mathrm{ml})$ & $\begin{array}{l}\text { Mean measured } \\
\text { concentration }(\mathrm{ng} / \mathrm{ml}) \pm S D(n=5)\end{array}$ & Precision $(\% \mathrm{CV})$ & Bias (\% difference) \\
\hline \multirow[t]{4}{*}{ Within-run } & LLOQ (13) & $10.96 \pm 0.71$ & 6.44 & $(-19.84-7.04)$ \\
\hline & QCL (52) & $51.42 \pm 5.69$ & 11.07 & $(-7.21-8.58)$ \\
\hline & QCM (260) & $261.44 \pm 19.18$ & 7.34 & $(-10.59-8.19)$ \\
\hline & QCH (416) & $401.95 \pm 24.84$ & 6.18 & $(-9.71-5.91)$ \\
\hline \multirow[t]{3}{*}{ Between-run } & LLOQ (13) & $12.86 \pm 0.61$ & 4.70 & $(-14.54-19.62)$ \\
\hline & QCL (52) & $54.32 \pm 2.09$ & 3.86 & $(-11.96-13.79)$ \\
\hline & QCH (416) & $403.03 \pm 4.47$ & 1.11 & $(-12.42-7.69)$ \\
\hline
\end{tabular}

LLOQ: Lower limit of quantification, QCL: Quality control low concentration, QCM: Quality control medium concentration, QCH: Quality control high concentration,

SD: Standard deviation, CV: Coefficient of variation, 6-MMP: 6-methylmercaptopurine

Table 5: Matrix effects for 6-MP and 6-MMP

\begin{tabular}{|c|c|c|c|c|c|c|c|}
\hline Blood lot & Concentration (ng/ml) & MF 6-MP (\%) & MF IS (\%) & MEIS (\%) & MF 6-MMP (\%) & MF IS (\%) & MEIS (\%) \\
\hline 1 & \multirow[t]{6}{*}{ QCL (104 for 6-MP, 52 for 6-MMP) } & 69.57 & 82.00 & 0.84 & 83.91 & 82.00 & 1.02 \\
\hline 2 & & 83.43 & 80.65 & 1.03 & 79.19 & 80.65 & 0.98 \\
\hline 3 & & 83.46 & 83.15 & 1.00 & 83.83 & 83.15 & 1.01 \\
\hline 4 & & 78.61 & 82.64 & 0.95 & 97.67 & 82.64 & 1.18 \\
\hline 5 & & 80.67 & 80.67 & 1.00 & 95.58 & 80.67 & 1.18 \\
\hline 6 & & 90.09 & 82.72 & 1.08 & 83.14 & 82.72 & 1.01 \\
\hline 1 & \multirow[t]{6}{*}{ QCH (820 for 6-MP, 416 for 6-MMP) } & 76.66 & 82.00 & 0.93 & 91.31 & 82.00 & 1.11 \\
\hline 2 & & 70.64 & 80.65 & 0.87 & 80.39 & 80.65 & 0.99 \\
\hline 3 & & 66.94 & 83.15 & 0.80 & 88.51 & 83.15 & 1.06 \\
\hline 4 & & 63.58 & 82.64 & 0.76 & 80.58 & 82.64 & 0.97 \\
\hline 5 & & 67.13 & 80.67 & 0.83 & 73.46 & 80.67 & 0.91 \\
\hline 6 & & 85.24 & 82.72 & 1.03 & 85.18 & 82.72 & 1.03 \\
\hline
\end{tabular}

MF: Matrix factors, MEIS: Internal standard normalized matrix factors, QCL: Quality control low concentration, QCH: Quality control high concentration,

6-MMP: 6-methylmercaptopurine, 6-MP: 6-mercaptopurine

Table 6: Stock solution stability of 6-MP, 6-MMP, and 5-FU

\begin{tabular}{|c|c|c|c|c|c|}
\hline Analyte & Temperature & Time & $\begin{array}{l}\text { Mean measured concentration } \\
(\mathrm{ng} / \mathrm{ml}) \pm S D(n=3)\end{array}$ & Precision $(\% \mathrm{CV})$ & Bias (\% diff) \\
\hline \multirow[t]{5}{*}{ 6-MP } & Room & $0 \mathrm{hr}$ & $834.77 \pm 58.60$ & 0.60 & $(0.43-3.87)$ \\
\hline & & $6 \mathrm{hrs}$ & $857.81 \pm 88.81$ & 0.27 & $(0.19-5.00)$ \\
\hline & & $24 \mathrm{hrs}$ & $987.54 \pm 50.18$ & 0.31 & $(0.22-3.76)$ \\
\hline & $-20^{\circ} \mathrm{C}$ & 8 days & $984.77 \pm 62.70$ & 0.21 & $(0.15-4.77)$ \\
\hline & & 16 days & $998.81 \pm 78.81$ & 0.47 & $(-0.34-10.34)$ \\
\hline \multirow[t]{4}{*}{ 6-MMP } & Room & $0 \mathrm{hr}$ & $878.54 \pm 91.50$ & 0.84 & $(0.59-9.23)$ \\
\hline & & $24 \mathrm{hrs}$ & $885.70 \pm 99.18$ & 0.26 & $(-0.18-10.01)$ \\
\hline & $-20^{\circ} \mathrm{C}$ & 8 days & $932.87 \pm 101.72$ & 0.04 & $(-0.03-5.99)$ \\
\hline & & 16 days & $977.41 \pm 120.11$ & 0.93 & $(0.66-6.43)$ \\
\hline \multirow[t]{5}{*}{$5-\mathrm{FU}$} & Room & $0 \mathrm{hr}$ & $911.24 \pm 95.53$ & 2.49 & $(1.76-2.98)$ \\
\hline & & $6 \mathrm{hrs}$ & $953.62 \pm 92.35$ & 1.70 & $(-1.21-1.78)$ \\
\hline & & $24 \mathrm{hrs}$ & $979.17 \pm 72.98$ & 0.29 & $(0.21-5.21)$ \\
\hline & $-20^{\circ} \mathrm{C}$ & 8 days & $1084.37 \pm 102.72$ & 0.09 & $(-0.06-3.22)$ \\
\hline & & 16 days & $1003.31 \pm 120.16$ & 2.54 & $(1.80-1.98)$ \\
\hline
\end{tabular}

Stock solution concentrations for 6-MP, 6-MMP and 5-FU $1000 \mathrm{ng} / \mathrm{ml}$. 6-MMP: 6-methylmercaptopurine, 6-MP: 6-mercaptopurine, 5-FU: 5-fluorouracil,

$\mathrm{CV}$ : Coefficient of variation 
Table 7: Short stability of 6-MP, 6-MMP as DBS at room temperature storage in sealed plastic bags containing silica gel desiccants

\begin{tabular}{|c|c|c|c|c|c|}
\hline Analyte & Concentration $(\mathrm{ng} / \mathrm{ml})$ & Time & $\begin{array}{l}\text { Mean measured } \\
\text { concentration }(\mathrm{ng} / \mathrm{ml}) \pm \operatorname{SD}(n=3)\end{array}$ & Precision (\% CV) & Recovery (\%) \\
\hline \multirow[t]{6}{*}{ 6-MP } & \multirow[t]{3}{*}{ QCL (104) } & $0 \mathrm{hr}$ & $99.81 \pm 7.29$ & 6.01 & 94.98 \\
\hline & & $12 \mathrm{hrs}$ & $106.60 \pm 5.03$ & 3.89 & 101.48 \\
\hline & & $24 \mathrm{hrs}$ & $103.45 \pm 7.29$ & 5.79 & 98.48 \\
\hline & \multirow{3}{*}{$\mathrm{QCH}(820)$} & $0 \mathrm{hr}$ & $878.95 \pm 40.53$ & 2.64 & 108.14 \\
\hline & & $12 \mathrm{hrs}$ & $843.60 \pm 43.23$ & 4.19 & 102.34 \\
\hline & & $24 \mathrm{hrs}$ & $866.71 \pm 86.95$ & 8.20 & 105.15 \\
\hline \multirow{6}{*}{ 6-MMP } & \multirow{3}{*}{ QCL (52) } & $0 \mathrm{hr}$ & $51.83 \pm 4.24$ & 6.31 & 104.98 \\
\hline & & $12 \mathrm{hrs}$ & $5.98 \pm 3.05$ & 4.44 & 107.17 \\
\hline & & $24 \mathrm{hrs}$ & $50.56 \pm 2.80$ & 4.25 & 102.53 \\
\hline & \multirow[t]{3}{*}{ QCH (416) } & $0 \mathrm{hr}$ & $389.35 \pm 21.64$ & 4.50 & 93.59 \\
\hline & & $12 \mathrm{hrs}$ & $379.37 \pm 19.62$ & 4.60 & 97.06 \\
\hline & & $24 \mathrm{hrs}$ & $391.37 \pm 31.04$ & 6.42 & 94.08 \\
\hline
\end{tabular}

6-MMP: 6-methylmercaptopurine, 6-MP: 6-mercaptopurine, CV: Coefficient of variation, QCL: Quality control low concentration, QCH: Quality control high concentration, DBS: Dried blood spots

Table 8: Autosampler stability of 6-MP, 6-MMP

\begin{tabular}{llllll}
\hline Analyte & Concentration $\mathbf{( n g / m l )}$ & Time & $\begin{array}{l}\text { Mean measured } \\
\text { concentration }(\mathbf{n g} / \mathbf{m l}) \pm \text { SD (n=3) }\end{array}$ & Precision (\% CV) & Recovery (\%) \\
\hline 6-MP & QCL (104) & $0 \mathrm{hrs}$ & $104.93 \pm 4.74$ & 3.69 & 9.47 \\
& & $24 \mathrm{hrs}$ & $110.44 \pm 7.35$ & 2.79 & 105.16 \\
& QCH (820) & $0 \mathrm{hrs}$ & $885.64 \pm 29.91$ & 3.50 & 106.21 \\
6-MMP & QCL (52) & $24 \mathrm{hrs}$ & $823.81 \pm 39.57$ & 1.60 & 108.01 \\
& & $0 \mathrm{hrs}$ & $55.30 \pm 1.15$ & 4.90 & 109.16 \\
& QCH (416) & $24 \mathrm{hrs}$ & $48.76 \pm 3.12$ & 2.29 & 98.17 \\
& 0 & $0 \mathrm{hrs}$ & $388.08 \pm 10.99$ & 3.57 & 93.29 \\
\hline
\end{tabular}

QCL: Quality control low concentration, QCH: Quality control high concentration, 6-MMP: 6-methylmercaptopurine, 6-MP: 6-mercaptopurine, CV: Coefficient of variation

Table 9: Result of 6-MP and 6-MMP in patients DBS sample

\begin{tabular}{lll}
\hline Donor & \multicolumn{2}{l}{ Concentration (pmol/8 x 10 $\mathbf{1 0}^{\mathbf{8}}$ erythrocytes) } \\
\cline { 2 - 3 } & $\mathbf{6 - M P}$ & $\mathbf{6 - M M P}$ \\
\hline 1 & 6.69 & 6.02 \\
2 & 10.37 & 16.59 \\
\hline 6
\end{tabular}

performed and as reported above, in selectivity parameter found no interfering signals from different hematocrit value from the blood (Fig. 2). The result of carry-over was given in Table 2; no carry-over was observed for any of the analytes including the IS. Values of accuracy and precision within-run and between-run fulfill the range of $\leq \pm 15 \%$ for QC samples and $\leq 20 \%$ for LLOQ (Tables 3 and 4 ). As shown in Table 5, the MF value than less $100 \%$, it concludes that indicated matrix compound causes ion suppression that can interfere with analyte ionization process, but $\% \mathrm{CV}$ values were within limits requested by EMEA guidelines [2,11-14]. Analytes in stock solution stable at least for 16 days storage of $-20^{\circ} \mathrm{C}$. Analyte in DBS was stable for 6 days at room temperature and $24 \mathrm{hrs}$ in the autosampler (stability data in Tables 6-8). The method has several advantages as compared to the literature $[1,10]$ such as minimum volume sample, simple sample preparation procedures, short analysis time ( 5 min per sample), and high sensitivity which rendered for the purpose of its application. The result of application toward childhood ALL patients in maintenance phase showed the concentration of 6-MP and 6-MMP; the results indicated that the methods used are not disturbed by the metabolic processes in vivo (Fig. 4). Monitoring the levels of 6-MP and 6-MMP were necessary to get the right information related to the availability of the metabolite 6-MP both the active metabolite and inactive metabolites.

\section{CONCLUSION}

The developed LC/MS-MS method is valid to analysis 6-MP and 6-MMP

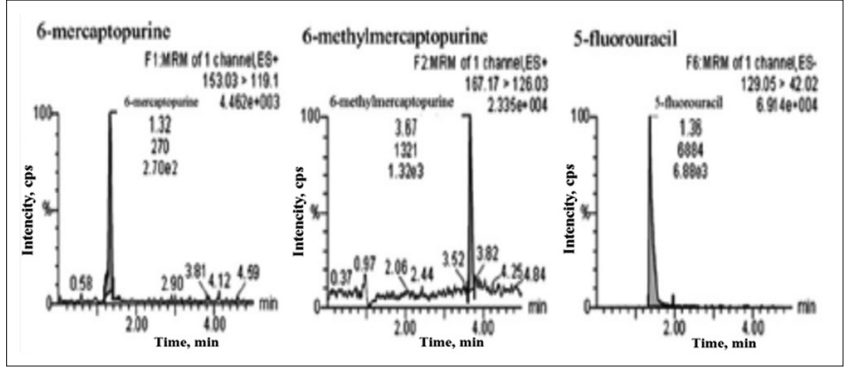

Fig. 4: Chromatograms showing the result of patient

in DBS simultaneous in vitro according to EMEA guidelines. The method was successfully applied to authentic capillary blood samples from two patients with ALL maintenance phase.

\section{ACKNOWLEDGMENT}

The authors are very thankful to KEMENRISTEKDIKTI the Republic of Indonesia for grant DRPM “Penelitian Disertasi Doktor 2016."

\section{REFERENCES}

1. Hawwa AF, Millership JS, Collier PS, McElnay JC. Development and validation of an HPLC method for the rapid and simultaneous determination of 6-mercaptopurine and four of its metabolites in plasma and red blood cells. J Pharm Biomed Anal 2009;49(2):401-9.

2. Tijare LK, Ranggari NT, Mahajan UN. A review on bioanalytical method development and validation. Asian J Pharm Clin Res 2016;9 Suppl 1:6-10.

3. Spooner N, Lad R, Barfield M. Dried blood spots as a sample collection technique for the determination of pharmacokinetics in clinical studies: Considerations for the validation of a quantitative bioanalytical method. Anal Chem 2009;81(7):1557-63.

4. Sharma A, Jaiswal S, Shukla M, Lal J. Dried blood spots: Concepts, 
present status, and future perspectives in bioanalysis. Drug Test Anal 2014;6(5):399-414.

5. Déglon J, Thomas A, Mangin P, Staub C. Direct analysis of dried blood spots coupled with mass spectrometry: Concepts and biomedical applications. Anal Bioanal Chem 2012;402(8):2485-98.

6. Evans C, Arnold M, Bryan P, Duggan J, James CA, Li W, et al. Implementing dried blood spot sampling for clinical pharmacokinetic determinations: Considerations from the IQ consortium microsampling working group. AAPS J 2015; 17:292-300.

7. De Kesel PM, Sadones N, Capiau S, Lambert WE, Stove CP. Hematocritical issues in quantitative analysis of dried blood spots: Challenges and solutions. Bioanalysis 2013;5(16):2023-41.

8. Capiau S, Stove VV, Lambert WE, Stove CP. Prediction of the hematocrit of dried blood spots via potassium measurement on a routine clinical chemistry analyzer. Anal Chem 2013;85(1):404-10.

9. Jakir SK, Rahul SS, Ritu MG. A rapid, sensitive and validated ultra performance liquid chromatography and tandem mass spectrometry method for determination of paromomycin in mice plasma: Aplication to pharmacokinetic study. Int J Pharm Pharm Sci 2017;9(5):86-90.
10. Kirchherr H, Shipkova M, von Ahsen N. Improved method for therapeutic drug monitoring of 6-thioguanine nucleotides and 6-methylmercaptopurine in whole-blood by LC/MSMS using isotopelabeled internal standards. Ther Drug Monit 2013;35(3):313-21.

11. European Medicines Agency (EMEA). Committee for Medicinal Products for Human Use (CHMP): Guideline on Bioanalytical Method Validation. London: European Medicines Agency; 2011.

12. Jager NG, Rosing H, Schellens JH, Beijnen JH. Procedures and practices for the validation of bioanalytical methods using dried blood spots: A review. Bioanalysis 2014;6(18):2481-514

13. Narottam P, Avanapu SR, Pigilli R. New method development and validation for the determination of febuxostat in human plasma by liquid chromatography-mass spectrometry. Int J Pharm Pharm Sci 2016;8(9):61-70.

14. Wael AA, Eyad MM, Israa HA, Tawfiq AA. Liquorice beverage effect on the pharmacokinetic parameters of atorvastatin, simvastatin, and lovastatin by liquid chromatography-mass spectroscopy/mass spectroscopy. Asian J Pharm Clin Res 2016;9:2174-9. 